Research Paper

\title{
Clinical Significance of Gender and Body Mass Index in Asian Patients with Colorectal Cancer
}

\author{
Chai Hong Rim¹, Chul Yong Kim², Dae Sik Yang ${ }^{3 凶}$, Won Sup Yoon ${ }^{1}$ \\ 1. Department of Radiation Oncology, Ansan Hospital, Korea University Medical College, Ansan, Gyeonggi-do, Republic of Korea \\ 2. Department of Radiation Oncology, Anam Hospital, Korea University Medical College, Seoul, Republic of Korea \\ 3. Department of Radiation Oncology, Guro Hospital, Korea University Medical College, Seoul, Republic of Korea \\ $\square$ Corresponding author: Dae Sik Yang, M.D., Ph.D., Department of Radiation Oncology, Guro Hospital, College of Medicine, Korea University, 148 \\ Gurodong-ro, Guro-gu, Seoul, Republic of Korea, 15355. Email: irionmphage@gmail.com; Tel +82 2626-1380 \\ (C) Ivyspring International Publisher. This is an open access article distributed under the terms of the Creative Commons Attribution (CC BY-NC) license \\ (https://creativecommons.org/licenses/by-nc/4.0/). See http://ivyspring.com/terms for full terms and conditions.
}

Received: 2018.07.13; Accepted: 2018.12.05; Published: 2019.01.01

\begin{abstract}
Objective: Colorectal cancer is a disease closely associated with anthropometric values. This study aimed to evaluate the clinical relevance of gender and body mass index (BMI) with colorectal cancer using a Korean nationwide cohort.

Methods: Data of colorectal cancer cohorts between 2012 and 2013 were acquired from the Health Insurance Review and Assessment Service. All patients underwent surgery due to colorectal cancers. Stage IV patients were excluded due to possible clinical heterogeneity. BMI was classified with the World Health Organization criteria.

Results: A total of 31,756 patients were analyzed. The underweight group had $33 \%$ higher risk of stage III disease $(p<0.001)$. The overweight and obese groups had $20 \%$ and $19 \%$ lower risk of stage III $(p<0.001$ and $p=0.002$, respectively). The underweight and obese groups had higher risk of longest hospitalization period quartile $(\geq 19$ days), with odds ratio of $2.26(p<0.001)$ and $1.33(p<0.001)$, respectively. The overweight group had a $22 \%$ lower risk of the longest hospitalization period quartile $(p=0.002)$. Females had $12 \%$ lower risk of distal cancer than males $(p<0.001)$. There was no significant relationship between cancer stage and gender. The proportions of patients who were $<50$ years and $\geq 70$ years old were higher in the females, and the proportions of patients in their 50s and 60s were higher in the males.

Conclusions: Cancer stages and hospitalization period varied depending on BMI. Disease location and the age distribution were affected by gender.
\end{abstract}

Key words: Gender, Body mass index, Colorectal neoplasms

\section{Introduction}

Colorectal cancer is among the leading causes of cancer death worldwide [1, 2]. In Korea and other East Asian countries, the incidence of colorectal cancer is increasing, which is attributed to changes in eating habits and popularization of cancer screening $[1,3]$. In Korea, the incidence of colorectal cancer per 100,000 people was 21.8 in 2000, which steadily increased until 2012, peaking at 58.3 and declining slightly to 53.1 in 2014.

Colorectal cancer is closely related to obesity. In the second expert report co-published by the World Cancer Research Fund (WCRF) and the American Institute of Cancer Research (AICR), obesity was classified as a convincing risk factor that could cause colorectal cancer [4]. Obesity was also related with increased morbidity, mortality, and prolonged hospital stay in previous studies [5-7]. Gender is another factor known to affect colorectal cancer status. Some researchers have reported that the stage or location of colorectal cancer varies according to gender of patients $[8,9]$.

This study was performed to demonstrate the clinical significance of body mass index (BMI) and gender using a large nationwide colorectal cancer patients cohort of Korea. 


\section{Methods}

\section{Data acquisition}

The Korean government has operated the National Health Insurance Service (NHIS) for over 30 years, covering more than $98 \%$ of the population [10]. The Korean Health and Insurance Review and Assessment Service (HIRA) has recorded claims and reimbursements made under NHIS and provide information about healthcare services. Clinical data of colorectal cancer cohorts between 2012 and 2013 were acquired from HIRA (http://opendata.hira.or.kr). The cohorts provided data of patients who underwent surgery due to colorectal cancer. The acquired data included age, gender, height, weight, date of surgery, cancer stage, hospitalization period, and insurance codes of disease. Based on the insurance codes provided, the patients included in the cohort were diagnosed with malignant neoplasm of the colon (C18), malignant neoplasm of the rectosigmoid junction (C19), and malignant neoplasm of the rectum (C20).

Because not all colorectal cancer patients in Korea are included in the cohort, we referred to the national cancer incidence rate provided by the Korean Statistical Information Service [11] to determine the proportion of the cohort among the total colorectal cancer cases nationwide.

\section{Cohort preparation for analysis}

The World Health Organization (WHO) criteria were used to classify BMI [12]: underweight was defined as BMI less than 18.5; normal weight 18.5-24.9; overweight, 25-29.9; and obese, 30 or above. The cases with insurance code C18 (malignant neoplasm of colon) were classified as proximal cancer, and the cases with C19 (malignant neoplasm of the rectosigmoid junction) or C20 (malignant neoplasm of the rectum) were categorized as distal cancer. Patients with stage IV in the cohorts were excluded from the analysis, because they might have heterogeneous nature such as much poor general condition, and the purpose of surgery might not be curative. If the patient records lack data in any of the variables, including height, weight, cancer stage, and hospitalization period, the records were excluded. Because the duration of the cohorts was as short as two years, and to maximize the statistical predictive power, statistical analysis was done with combined cohort summing cohorts of 2012 and 2013.

\section{Statistical analysis}

Univariate analysis between BMI/gender with clinical variables, was performed using the Pearson chi-square test. Multivariate analysis was performed using logistic regression analysis. Regarding age groups, semantic interpretation was not made with multivariate analysis because certain age group could not represent a normal reference group. All analyses were performed using the IBM SPSS statistics 20 (IBM Inc., NY, US).

\section{Results}

\section{National incidence and evaluation of cohorts}

In 2012, the total number of colorectal cancer cases in Korea was 29,366 and was calculated as 58.3 cases per 100,000 people. At this year, HIRA recorded 18,310 patient cases, comprising $62.4 \%$ of the total national cases. A total of 2,169 stage IV cases and 409 patient records with missing data were excluded, and 15,732 patient records were finally included for analysis.

In 2013, 27,870 colorectal cancer cases occurred in Korea, which can be estimated to 55.1 cases per 100,000 people. The HIRA cohort comprised $66.1 \%$ with 18,430 patient records. After excluding 2,317 stage IV patient records and 89 records with missing data, 16,024 patient records were analyzed. Overall, a total of 31,756 colorectal cancer records, which accounted for $64.2 \%$ of all patients in the country, were used for analysis, including HIRA cohorts of 2012 and 2013.

\section{Univariate analysis of BMI and clinical variables}

The number of underweight, normal weight, overweight, and obese patients in the total cohort was 1670 (5.3\%), 20,184 (63.6\%), 8,946 (28.2\%), and 956 $(3.0 \%)$, respectively. When analyzing all four BMI groups, and between normal weight and the other three groups, statistically significant difference of distribution $(\mathrm{p}<0.05)$ of clinical variables was noted in most of the analyses. Only the analyses comparing normal weight and underweight, normal weight and overweight regarding age, normal weight and overweight, and normal weight and obese assessing disease locations were not statistically significant. The results of initial analysis are described in Table 1.

\section{Multivariate analysis of BMI and clinical variables}

The underweight group had high risk for advanced stage cancer. The risks of stage II and stage III disease were $67 \%$ and $33 \%$ higher in the underweight group than in the normal weight group, respectively ( $p<0.001$ and $p<0.001$, respectively). The overweight and obese groups had a lower risk of having advanced stage cancer than the normal weight group. Compared with the normal weight group, the overweight group showed $20 \%$ lower risk to have both stage II and III cancer $(p<0.001$ and $p<0.001$, 
respectively), and the obese group showed $40 \%$ and $19 \%$ lower risk to have stage II and III cancer $(p<0.001$ and $p=0.007$, respectively).

Hospitalization period was shown to be relatively short in the overweight group. The overweight group had a $22 \%$ lower risk for the highest quartile (days of hospital stay $>19$ days) than the normal weight group $(\mathrm{p}<0.001)$. The obese group had $33 \%$ high risk for the highest quartile $(p=0.002)$. In the underweight group, the risk for the highest quartile was as high as $126 \%$ compared with that in the normal weight group $(\mathrm{p}<0.001)$.


Figure 1. Mean values of the cancer stages and hospitalization period according to body mass index (BMI) categories. (A) Cancer stages according to BMI categories. The overweight group had the lowest mean value of cancer stage, and the underweight group had the highest mean value. (B) Hospitalization period according to the BMI categories. Among all groups, mean LOS was lowest in the overweight group and longest in the underweight group. Abbreviations: $\mathrm{Cl}$, confidence interval; $\mathrm{NIH}$, National Institute of Health.

For gender, no difference was noted between the normal weight and underweight and normal weight and overweight groups. The number of female patients in the obese group was significantly higher than that in the normal weight group $(\mathrm{p}<0.001$; OR:
1.48; 95\% confidence interval (CI): 1.30-1.68). Disease location was not significantly different in all analyses, including that in the normal weight compared with the underweight, overweight, and obese groups. The results of the above analysis are shown in Table 2. Mean value distribution according to BMI categories of cancer stage and hospitalization period are exhibited in Figure 1.

\section{Analysis of Gender and clinical variables}

The distribution of patients according to gender and the results of the univariate analysis are described in Table 3. In comparison between genders, there were significant differences according to age group, BMI, and disease location (Ps<0.001). Regarding age groups, the proportions of patients who were $<50$ years and $\geq 70$ years old were higher in the females, and the proportions of patients in their 50s and 60s were higher in the males (Figure 2). Cancer stage and hospitalization period showed no difference according to gender ( $p=0.111,0.720$, respectively). In multivariate analysis, the female cohort had more of obese patients $(\mathrm{p}<0.001$; OR 1.49; 95\% CI 1.31 - 1.70), and less of distal colorectal cancer patients $(\mathrm{p}<0.001$; OR $0.88 ; 95 \%$ CI $0.84-0.92$ ) than the male cohort. The results of multivariate analysis are also described in Table 3.

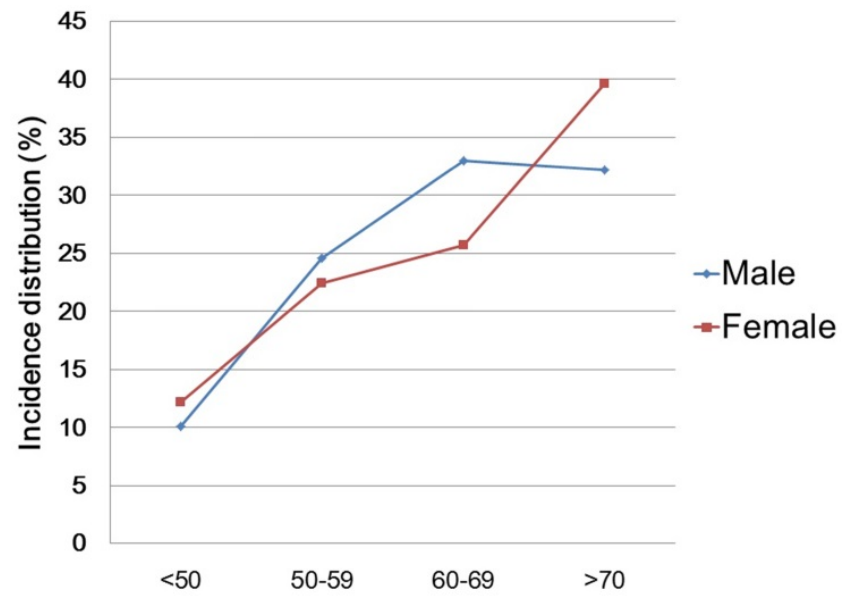

Figure 2. Incidence distribution according to age groups and gender

\section{Discussion}

This study showed clinical relevance of BMI and gender, with colorectal cancer of Asians. Cancer stage was higher in the underweight group and lower in the overweight and obese groups than in the normal weight group. Hospitalization period was longer than normal weight group, in the underweight and obese groups. In particular, the underweight group showed a significantly high risk of the top quartile of hospitalization period. 
Table 1. Univariate analysis of body mass index and clinical variables

\begin{tabular}{|c|c|c|c|c|c|c|c|c|c|}
\hline & & \multicolumn{8}{|c|}{ Categories (body mass index) } \\
\hline & & UW (<18.5) & NW (18.5 to 24.9$)$ & OW (25 to 29.9$)$ & $\mathrm{OB}(\geq 30)$ & $\mathrm{p}$ value & & & \\
\hline & & $\mathrm{n}(\%)$ & $\mathrm{n}(\%)$ & $\mathrm{n}(\%)$ & $\mathrm{n}(\%)$ & all & NW Vs. UW & NW Vs. OW & NW Vs. OB \\
\hline \multicolumn{10}{|l|}{ Age } \\
\hline & $<50$ & 178 (10.7) & $2,202(10.9)$ & $987(11.0)$ & 112 (11.7) & & & & \\
\hline & 50 to 59 & $310(18.6)$ & $4,772(23.6)$ & $2,199(24.6)$ & $261(27.3)$ & & & & \\
\hline & 60 to 69 & $458(27.4)$ & $5,967(29.6)$ & $2,851(31.9)$ & $290(30.3)$ & & & & \\
\hline & $\geq 70$ & $724(43.4)$ & $7,243(35.9)$ & $2,909(32.5)$ & $293(30.6)$ & $<0.001$ & $<0.001$ & $<0.001$ & 0.005 \\
\hline \multicolumn{10}{|c|}{ Gender } \\
\hline & Male & $995(59.6)$ & $12,249(60.7)$ & $5,427(60.7)$ & $491(51.4)$ & & & & \\
\hline & Female & $675(40.4)$ & $7,935(39.3)$ & $3,519(39.3)$ & 465 (48.6) & $<0.001$ & 0.374 & 0.971 & $<0.001$ \\
\hline \multicolumn{10}{|c|}{ Cancer stage } \\
\hline & I & $276(16.5)$ & $4,924(24.4)$ & $2,622(29.3)$ & $295(30.9)$ & & & & \\
\hline & II & $706(42.3)$ & $6,722(33.3)$ & $2,781(31.1)$ & $241(25.2)$ & & & & \\
\hline & III & $688(41.2)$ & $8,538(42.3)$ & $3,543(39.6)$ & $420(43.9)$ & $<0.001$ & $<0.001$ & $<0.001$ & $<0.001$ \\
\hline \multicolumn{10}{|c|}{ Hospitalization period (days) } \\
\hline & $<11$ & $336(20.1)$ & $6,193(30.7)$ & $3,060(34.2)$ & $264(27.6)$ & & & & \\
\hline & 11 to 13 & $326(19.5)$ & $4,956(24.6)$ & $2,229(24.9)$ & $259(27.1)$ & & & & \\
\hline & 14 to 18 & $366(21.9)$ & $4,221(20.9)$ & $1,887(21.1)$ & $185(19.4)$ & & & & \\
\hline & $\geq 19$ & $642(38.4)$ & $4,814(23.9)$ & $1,770(19.8)$ & $248(25.9)$ & $<0.001$ & $<0.001$ & $<0.001$ & 0.047 \\
\hline \multicolumn{10}{|c|}{ Location of disease } \\
\hline & Proximal & $626(37.5)$ & $6,926(34.3)$ & $3,067(34.3)$ & $312(32.6)$ & & & & \\
\hline & Distal & $1,044(62.5)$ & $13,258(65.7)$ & $5,879(65.7)$ & $644(67.4)$ & 0.037 & 0.009 & 0.959 & 0.285 \\
\hline Total & & $1,670(100)$ & $20,184(100)$ & $8,946(100)$ & $956(100)$ & 31,756 & & & \\
\hline
\end{tabular}

Abbreviations: UW, underweight; $\mathrm{NO}$, normal weight; OW, overweight; OB, obese

Table 2. Multivariate analysis of body mass index and clinical variables

\begin{tabular}{|c|c|c|c|c|c|c|}
\hline & NW (18.5-24.9) compared & & & & & \\
\hline & UW (<18.5), OR $(95 \%$ CI) & $\mathrm{p}$ value & OW (25-29.9), OR (95\% CI) & $\mathrm{p}$ value & OB $(\geq 30)$, OR $(95 \% \mathrm{CI})$ & $\mathrm{p}$ value \\
\hline \multicolumn{7}{|l|}{ Age } \\
\hline$<50$ & ref & & ref & & ref & \\
\hline 50 to 59 & $0.80(0.66-0.97)$ & 0.024 & & 0.658 & & 0.438 \\
\hline 60 to 69 & & 0.358 & & 0.142 & & 0.934 \\
\hline$\geq 70$ & & 0.267 & & 0.059 & $0.79(0.63-1.00)$ & 0.044 \\
\hline \multicolumn{7}{|l|}{ Gender } \\
\hline Male & ref & & ref & & ref & \\
\hline Female & & 0.569 & & 0.579 & $1.48(1.30-1.68)$ & $<0.001$ \\
\hline \multicolumn{7}{|l|}{ Cancer stage } \\
\hline I & ref & & ref & & ref & \\
\hline II & $1.67(1.44-1.93)$ & $<0.001$ & $0.80(0.75-0.86)$ & $<0.001$ & $0.60(0.50-0.71)$ & $<0.001$ \\
\hline III & $1.33(1.15-1.53)$ & $<0.001$ & $0.80(0.75-0.85)$ & $<0.001$ & $0.81(0.69-0.94)$ & 0.007 \\
\hline \multicolumn{7}{|c|}{ Hospitalization period (days) } \\
\hline$<11$ & ref & & ref & & ref & \\
\hline 11 to 13 & $1.18(1.01-1.39)$ & 0.035 & $0.92(0.86-0.98)$ & 0.013 & $1.26(1.06-1.50)$ & 0.010 \\
\hline 14 to 18 & $1.51(1.29-1.76)$ & $<0.001$ & $0.93(0.87-1.00)$ & 0.045 & & 0.356 \\
\hline$\geq 19$ & $2.26(1.96-2.59)$ & $<0.001$ & $0.78(0.72-0.83)$ & $<0.001$ & $1.33(1.11-1.60)$ & 0.002 \\
\hline \multicolumn{7}{|l|}{ Location of disease } \\
\hline Proximal & ref & & ref & & ref & \\
\hline Distal & & 0.243 & & 0.511 & & 0.513 \\
\hline
\end{tabular}

Abbreviations: UW, underweight; $\mathrm{OR}$, odd ratio; $\mathrm{CI}$, confidence interval; $\mathrm{NO}$, normal weight; $\mathrm{OW}$, overweight; $\mathrm{OB}$, obese

The research results on the relationship between obesity and cancer stage are conflicting. Some researchers suggested that high BMI might be associated with advanced colon cancer $[8,13,14]$. Other investigators have reported no association between obesity and colon cancer stage [15-17], and a recent meta-analysis indicated that BMI is not related to pathologic status of rectal cancer [6]. In our study, the risk of advanced cancer stage in the overweight or obese groups was lower than in the normal weight group. Although further investigation is needed to explain the result, we hypothesize that BMI categorization might be the partial cause of the difference from the previous studies. Most studies have described the distinctive status of diseases in obese populations, but the proportion of obese patients in our study was too small. It is also possible cause that we only did analysis using BMI, and did not perform body composition analysis $[18,19]$. 
Table 3. Analyses between gender and clinical variables

\begin{tabular}{|c|c|c|c|c|c|c|}
\hline & & \multicolumn{2}{|c|}{ Univariate analysis } & \multicolumn{3}{|c|}{ Multivariate analysis (compared to male) } \\
\hline & & $\begin{array}{l}\text { Male } \\
\mathrm{n}(\%)\end{array}$ & $\begin{array}{l}\text { Female } \\
\mathrm{n}(\%)\end{array}$ & $\mathrm{p}$ value & Female, OR (95\% CI) & $\mathrm{p}$ value \\
\hline \multicolumn{7}{|l|}{ Age } \\
\hline & $<50$ & $1942(10.1)$ & $1537(12.2)$ & & ref & \\
\hline & 50 to 59 & $4718(24.6)$ & $2824(22.4)$ & & $0.76(0.70-0.82)$ & $<0.001$ \\
\hline & 60 to 69 & $6324(33.0)$ & $3242(25.7)$ & & $0.65(0.60-0.70)$ & $<0.001$ \\
\hline & $\geq 70$ & $6178(32.2)$ & $4991(39.6)$ & $<0.001$ & & 0.586 \\
\hline \multicolumn{7}{|l|}{ BMI } \\
\hline & Normal weight & $12249(63.9)$ & $7935(63.0)$ & & ref & \\
\hline & Underweight & $995(5.2)$ & $675(5.4)$ & & & 0.727 \\
\hline & Overweight & $5427(28.3)$ & $3519(27.9)$ & & & 0.55 \\
\hline & Obese & $491(2.6)$ & $465(3.7)$ & $<0.001$ & $1.49(1.31-1.70)$ & $<0.001$ \\
\hline \multicolumn{7}{|c|}{ Cancer stage } \\
\hline & $\mathrm{I}$ & $4963(25.9)$ & $3154(25.0)$ & & ref & \\
\hline & II & $6322(33.0)$ & $4128(32.8)$ & & & 0.929 \\
\hline & III & $7877(41.1)$ & $5312(42.2)$ & 0.111 & & 0.09 \\
\hline \multicolumn{7}{|c|}{ Hopitalization period } \\
\hline & $<11$ & $5969(31.2)$ & $3884(30.8)$ & & ref & \\
\hline & 11 to 13 & $4714(24.6)$ & $3056(24.3)$ & & & 0.912 \\
\hline & 14 to 18 & $4001(20.9)$ & $2658(21.1)$ & & & 0.962 \\
\hline & $\geq 19$ & $4478(23.4)$ & $2996(23.8)$ & 0.720 & & 0.603 \\
\hline \multicolumn{7}{|c|}{ Location of disease } \\
\hline & Proximal & $6362(33.2)$ & $4569(36.3)$ & & ref & \\
\hline & Distal & $12800(66.8)$ & $8025(63.7)$ & $<0.001$ & $0.88(0.84-0.92)$ & $<0.001$ \\
\hline Total & & 19,162 & 12594 & & & \\
\hline
\end{tabular}

Abbreviations: OR, odd ratio; $\mathrm{CI}$, confidence interval; BMI, body mass index

Conventional wisdom among surgeons is that obese patients have more medical comorbidities, and the risk of adverse surgical outcome is high [20]. A recent meta-analysis supported this theory with the result that obesity was related with increased risk of surgical complications [6]. However, some previous studies reported that obesity might not be a risk factor for increased hospitalization period or postoperative complications [21-23].

A recent study using the nationwide inpatient database of the US reported that preobese and obese patients had short hospitalization period [7]. However, the hospitalization period was increased at normal and severe obesity (BMI $\geq 40$ ) groups, which was shown as a U-shaped curve. In our study, the overweight group had a shorter hospitalization period than the normal weight group, and the obese group had a high risk of long hospitalization period. The proportion of patients with BMI $\geq 30$ was over $70 \%$ in the US study, whereas in our study it was only $3 \%$. Considering that the BMI of Asian people is generally lower than that of Western people, and if we hypothesize that the obese group in our study and severe obesity group in the US study reflect similar biologic degree of obesity, the two studies might be regarded with similar context.

Although it is a less rigorously researched subject, being underweight is also a clinical concern in colorectal cancer. Mullen et al. [20] reported that underweight patients who underwent intraabdominal cancer surgery have high postoperative mortality (odds ratio: 5.24; 95\% CI: 1.70-16.2). Tjeertes et al. [24] also found that complication and morality rates were significantly worse in underweight patients who underwent general surgery.

Several explanations were suggested for this phenomenon. The underweight group may be composed of more smokers or people who have experienced weight loss due to chronic illness $[25,26]$. Recent weight loss $>10 \%$ or low albumin levels have also been associated with postoperative morbidity and mortality [27-29]. In our study, the underweight group had increased risk of higher cancer stage, which might be associated with postoperative outcome and longer hospitalization period. Our results are consistent with previous studies.

Colorectal cancer is a disease closely associated with gender. In our study, the proportion of female patients was slightly higher in age group under 50 years, male patients were higher in groups of 50 s and $60 \mathrm{~s}$, and female patients were higher in group over 70 years of age. The number of incidence were higher in the male patients across all age groups. This trend is consistent with the results of two large cohort studies using the United States Surveillance, Epidemiology and End Results (SEER) database [30, 31]. The cumulative protective effect of estrogen for up to 20-25 years after menopause, and reduction of colorectal cancer risk with use of hormone replacement therapy, have been suggested as hypotheses to explain these results [32-34].

Our study showed that female patients were less likely to have distal colon cancer than male patients. This finding is consistent with most of the related reports [8, 35-37]. Differences in lifestyle and eating habits [38-42], and differences in screening rates are 
possible explanations [30, 43], but further research is needed to find the reason for this result.

Male patients are generally known to have more advanced colorectal cancer [8, 44, 45]. A meta-analysis reported that male patients had more advanced stage of colorectal cancer than females [9]. The etiology for the gender difference is still uncertain, but preventive effect of estrogen and progestins [46, 47], less use of smoking and alcohol [48-50], and genetic difference have been suggested as possible hypotheses [44, 51].

In our study, multivariate analysis showed no significant difference in cancer stages, and proportions according to stages were almost similar between men and women. In a large epidemiologic study using the SEER database from 1975 to 2006, men had significantly higher incidence of colorectal cancer in all stages. However, the differences of incidence between men and women were $18.3 \%$, $12.5 \%$ and $7.7 \%$, in localized, regional, and distant stage of cancer, respectively; the differences were decreased as the disease were getting advanced [37]. Considering the results of our study and the SEER database study, further investigation might be needed about the past knowledge that male patients generally have a higher incidence of advanced colorectal cancer.

Several limitations should be taken into consideration to interpret the present study. Our study is mainly observational, and the analysis was performed with narrow range of clinical information. The main limitation of our study is that it is impossible to perform detailed analyses to clearly define the cause of results. Nevertheless, this study is still valuable for showing the clinical significance of BMI and gender in Asian patients with colorectal cancer, who have been less studied and may have different obesity characteristics from the Western population.

As socioeconomic status is known to be closely related to obesity [52], diagnostic chance from cancer screening might be increased in a certain BMI group. In Korea, the national cancer screening program has provided free services for those with bottom 50\% income and subsidized $80 \%$ of costs for higher income group, from 2006 [53]. Considering a study about relationship between socioeconomic status and obesity of Koreans, dose-response relationship was noted between income and obesity for men but not for women [54]. However, numeral difference of median BMI between lowest and highest income quartile was only 1.4, and median values of BMI in all quartiles were narrowly ranged from 22.5 to 23.9. Although possible bias could not be fully controlled, the likelihood that obesity and related socioeconomic differences affect the screening chance and consequently affected the outcome of this study might be less than moderate.

\section{Conclusion}

In our study, using WHO BMI classification, being obese or underweight was related with cancer stage and hospitalization period but not with tumor location. Underweight and obese patients showed prolonged hospitalization period, whereas preobese patients had shorter hospitalization period. Underweight patients had high cancer stages, whereas overweight and obese patients have low stages. Female patients had a lower incidence rate of distal colon cancer than male patients, and there was no significant correlation between cancer stage and gender. There were relatively more female patients in the $<50$ and $\geq 70$ of ages and more male patients in the 50 s and 60s. Our study is one of the largest studies investigating clinical relevance of gender and BMI with colorectal cancer in Asians. Several distinctive results in our study offer possibilities of future research.

\section{Abbreviations}

BMI: body mass index; WCRF: World Cancer Research Fund; AICR: American Institute of Cancer Research; NHIS: National Health Insurance Service; HIRA: the Korean Health Insurance Review and Assessment Service; WHO: World Health Organizaion; CI: confidence interval; SEER: Surveillance, Epidemiology and End Results.

\section{Acknowledgements}

Supported by Korea University Ansan Hospital Grant (O1801171).

\section{Competing Interests}

The authors have declared that no competing interest exists.

\section{References}

1. Jung KW, Won YJ, Kong HJ, Oh CM, Cho H, Lee DH, et al. Cancer statistics in Korea: incidence, mortality, survival, and prevalence in 2012. Cancer Res Treat. 2015; 47: 127-41.

2. Ferlay J, Soerjomataram I, Dikshit R, Eser S, Mathers C, Rebelo M, et al. Cancer incidence and mortality worldwide: sources, methods and major patterns in GLOBOCAN 2012. Int J Cancer. 2015; 136: E359-86.

3. Sung JJ, Lau JY, Goh KL, Leung WK. Increasing incidence of colorectal cancer in Asia: implications for screening. Lancet Oncol. 2005; 6: 871-6.

4. World Cancer Research Fund / American Institute for Cancer Research. Food, Nutrition, Physical Activity, and the Prevention of Cancer: a Global Perspective. Washington DC: AICR, 2007

5. Tsaousi G, Kokkota S, Papakostas P, Stavrou G, Doumaki E, Kotzampassi K. Body composition analysis for discrimination of prolonged hospital stay in colorectal cancer surgery patients. Eur J Cancer Care (Engl). 2017;26(6):e12491.

6. Qiu Y, Liu Q, Chen G, Wang W, Peng K, Xiao W, et al. Outcome of rectal cancer surgery in obese and nonobese patients: a meta-analysis. World J Surg Oncol. 2015; 14: 23

7. Akinyemiju T, Meng Q, Vin-Raviv N. Association between body mass index and in-hospital outcomes: Analysis of the nationwide inpatient database. Medicine. 2016; 95: e4189. 
8. Brandstedt J, Wangefjord S, Nodin B, Gaber A, Manjer J, Jirstrom K. Gender, anthropometric factors and risk of colorectal cancer with particular reference to tumour location and TNM stage: a cohort study. Biol Sex Differ. 2012; 16: 1.

9. Nguyen SP, Bent S, Chen YH, Terdiman JP. Gender as a Risk Factor for Advanced Neoplasia and Colorectal Cancer: A Systematic Review and Meta-analysis. Clin Gastroenterol Hepatol. 2009; 7: 676-81.

10. Kwon S. Thirty years of national health insurance in South Korea: lessons for achieving universal health care coverage. Health Policy Plan. 2009; 24: 63-71.

11. Korean Statistical Infomation Service (KOSIS), accessed June 09, 2017. Avilable from: http:/ / kosis.kr.

12. World Health Organization. "Body mass index - BMI". Available at: http://www.euro.who.int/en/health-topics/disease-prevention/nutrition/a -healthy-lifestyle/body-mass-index-bmi. Retrieved June 09, 2017.

13. Kwon HJ, Kim HJ, Park YS, Lim JH, Park KJ, Shin CM, et al. Body Mass Index as a Predictor of Advanced Colorectal Neoplasia. J Cancer Prev. 2013; 18: 144-8.

14. Siddiqui A, N. H, Sahdala P, Nazario HE, Mahgoub A, Patel M, et al. Obesity is associated with an increased prevalence of advanced adenomatous colon polyps in a male veteran population. Dig Dis Sci. 2009; 54: 1560-4.

15. MacInnis RJ, English DR, Hopper JL, Haydon AM, Gertig DM, Giles GG. Body size and composition and colon cancer risk in men. Cancer Epidemiol Biomarkers Prev. 2004; 13: 553-9.

16. Neumann K, Mahmud SM, McKay A, Park J, Metcalfe J, Hochman DJ. Is obesity associated with advanced stage or grade of colon cancer? Can J Surg. 2015; 58: 140-2.

17. MacInnis RJ, English DR, Hopper JL, Gertig DM, Haydon AM, Giles GG. Body size and composition and colon cancer risk in women. Int J Cancer. 2006; 118: 1496-500.

18. Berstad P, Haugum B, Helgeland M, Bukholm I, Almendingen K. Preoperative body size and composition, habitual diet, and post-operative complications in elective colorectal cancer patients in Norway. J Hum Nutr Diet. 2013; 26: $359-68$.

19. Malietzis G, Aziz O, Bagnall NM, Johns N, Fearon KC, Jenkins JT. The role of body composition evaluation by computerized tomography in determining colorectal cancer treatment outcomes: a systematic review. Eur J Surg Oncol. 2015; 41: 186-96.

20. Mullen JT, Davenport DL, Hutter MM, Hosokawa PW, Henderson WG, Khuri $\mathrm{SF}$, et al. Impact of body mass index on perioperative outcomes in patients undergoing major intra-abdominal cancer surgery. Ann Surg Oncol. 2008; 15: 2164-72.

21. Hawn MT, Bian J, Leeth RR, Ritchie G, Allen N, Bland KI, et al. Impact of obesity on resource utilization for general surgical procedures. Ann Surg. 2005; 241: 821-6; discussion 6-8.

22. Dindo D, Muller MK, Weber M, Clavien PA. Obesity in general elective surgery. Lancet. 2003; 361: 2032-5.

23. Klasen J, Junger A, Hartmann B, Jost A, Benson M, Virabjan T, et al. Increased body mass index and peri-operative risk in patients undergoing non-cardiac surgery. Obes Surg. 2004; 14: 275-81.

24. Tjeertes EK, Hoeks SE, Beks SB, Valentijn TM, Hoofwijk AG, Stolker RJ. Obesity--a risk factor for postoperative complications in general surgery? BMC Anesthesiol. 2015; 15: 112.

25. Galal W, van Gestel Y, Hoeks SE, Sin DD, Winkel TA, Bax JJ, et al. The obesity paradox in patients with peripheral arterial disease. Chest. 2008; 134: 925-30.

26. Willett WC, Dietz WH, Colditz GA. Guidelines for healthy weight. N Engl J Med. 1999; 341: 427-34.

27. S. Palma, A. Cosano, M. Mariscal, G. Martínez-Gallego, M. Medina-Cuadros, Delgado-Rodríguez M. Cholesterol and serum albumin as risk factors for death in patients undergoing general surgery. Br J Surg. 2007; 94: 369-75.

28. Oh CA, Kim DH, Oh SJ, Choi MG, Noh JH, Sohn TS, et al. Nutritional risk index as a predictor of postoperative wound complications after gastrectomy. World J Gastroenterol. 2012; 18: 673-8.

29. Bozzetti F, Gianotti L, Braga M, Di Carlo V, Mariani L. Postoperative complications in gastrointestinal cancer patients: the joint role of the nutritional status and the nutritional support. Clin Nutr. 2007; 26: 698-709.

30. Brenner $\mathrm{H}$, Hoffmeister $\mathrm{M}$, Arndt $\mathrm{V}$, Haug U. Gender differences in colorectal cancer: implications for age at initiation of screening. Br J Cancer. 2007; 96: $828-31$.

31. Purim O, Gordon N, Brenner B. Cancer of the colon and rectum: Potential effects of sex-age interactions on incidence and outcome. Med Sci Monit. 2013; 19: 203-9.

32. Singh S, Langman MJS. Estrogen and Colonic Epithelial-Cell Growth. Gut. 1995: 37: 737-9.

33. Kennelly R, Kavanagh DO, Hogan AM, Winter DC. Oestrogen and the colon: potential mechanisms for cancer prevention. Lancet Oncol. 2008; 9: 385-91.

34. Chlebowski RT, Rodabough RJ, Wactawski-Wende J. Estrogen plus progestin and colorectal cancer in postmenopausal women - Reply. N Engl J Med. 2004; 350: $2418-9$.

35. Nelson RL, Dollear T, Freels S, Persky V. The relation of age, race, and gender to the subsite location of colorectal carcinoma. Cancer. 1997; 80: 193-7.

36. Wu XC, Chen VW, Steele B, Ruiz B, Fulton J, Liu LH, et al. Subsite-specific incidence rate and stage of disease in colorectal cancer by race, gender, and age group in the United States, 1992-1997. Cancer. 2001; 92: 2547-54.

37. Abotchie PN, Vernon SW, Du XLL. Gender Differences in Colorectal Cancer Incidence in the United States, 1975-2006. J Womens Health (Larchmt). 2012; 21: 393-400.
38. Steinmetz KA, Potter JD. Food-Group Consumption and Colon Cancer in the Adelaide Case-Control Study .1. Vegetables and Fruit. Int J Cancer. 1993; 53: 711-9.

39. Young TB, Wolf DA. Case-Control Study of Proximal and Distal Colon Cancer and Diet in Wisconsin. Int J Cancer. 1988; 42: 167-75.

40. Knekt P, Hakulinen T, Leino A, Heliovaara M, Reunanen A, Stevens R. Serum albumin and colorectal cancer risk. Eur J Clin Nutr. 2000; 54: 460-2.

41. Lee KJ, Inoue M, Otani T, Iwasaki M, Sasazuki S, Tsugane S. Physical activity and risk of colorectal cancer in Japanese men and women: the Japan Public Health Center-based prospective Study. Cancer Causes Control. 2007; 18: 199-209.

42. Thune I, Lund E. Physical activity and risk of colorectal cancer in men and women. Br J Cancer. 1996; 73: 1134-40.

43. Rim JH, Youk T, Kang JG, Park BK, Gee HY, Kim JH, et al. Fecal Occult Blood Test Results of the National Colorectal Cancer Screening Program in South Korea (2006-2013). Sci Rep. 2017;7(1):2804

44. Cook MB, McGlynn KA, Devesa SS, Freedman ND, Anderson WF. Sex disparities in cancer mortality and survival. Cancer Epidemiol Biomarkers Prev. 2011; 20: 1629-37.

45. Kolligs FT, Crispin A, Munte A, Wagner A, Mansmann U, Goke B. Risk of Advanced Colorectal Neoplasia According to Age and Gender. PLoS One. 2011;6(5):e20076

46. Newcomb PA, Zheng YY, Chia VM, Morimoto LM, Doria-Rose VP, Templeton $\mathrm{A}$, et al. Estrogen plus progestin use, microsatellite instability, and the risk of colorectal cancer in women. Cancer Res. 2007; 67: 7534-9.

47. Vera PGC, Rada GG. Risks and benefits of estrogen plus progestin in healthy postmenopausal women. principal results from the women's health initiative randomized controlled trial. Revista Medica De Chile. 2003; 131: 951-3.

48. Cho EY, Smith-Warner SA, Ritz J, van den Brandt PA, Colditz GA, Folsom AR, et al. Alcohol intake and colorectal cancer: A pooled analysis of 8 cohort studies. Ann Intern Med. 2004; 140: 603-13.

49. Tsong WH, Koh WP, Yuan JM, Wang R, Sun CL, Yu MC. Cigarettes and alcohol in relation to colorectal cancer: the Singapore Chinese Health Study. Br J Cancer. 2007; 96: 821-7.

50. Botteri E, Iodice S, Raimondi S, Maisonneuve P, Lowenfels AB. Cigarette smoking and adenomatous polyps: A meta-analysis. Gastroenterology. 2008; 134: 388-95.

51. Press OA, Zhang $W$, Gordon MA, Yang DY, Lurje G, Lqbal S, et al. Gender-related survival differences associated with EGFR Polymorphisms in metastatic colon cancer. Cancer Res. 2008; 68: 3037-42.

52. Sobal J, Stunkard AJ. Socioeconomic status and obesity: a review of the literature. Psychol bull. 1989; 105: 260-75.

53. Kim S, Hwang J. Assessment of trends in socioeconomic inequalities in cancer screening services in Korea, 1998-2012. Int J Equity Health. 2016; 15: 30.

54. Yoon YS, Oh SW, Park HS. Socioeconomic status in relation to obesity and abdominal obesity in Korean adults: a focus on sex differences. Obesity (Silver Spring). 2006; 14: 909-19. 